\title{
Gastrointestinal events and association with initiation of treatment for osteoporosis
}

This article was published in the following Dove Press journal:

ClinicoEconomics and Outcomes Research

25 November 2015

Number of times this article has been viewed

\section{Ankita Modil \\ Ethel S Siris ${ }^{2}$ \\ Jackson Tang ${ }^{3}$ \\ Shiva Sajjan' \\ Shuvayu S Sen'}

'Center for Observational and Real-World Evidence, Merck \& Co., Inc, Kenilworth, NJ, ${ }^{2}$ Toni Stabile Osteoporosis Center, Columbia University Medical Center, NY Presbyterian Hospital, New York, NY, ${ }^{3}$ Asclepius Analytics Ltd, Brooklyn, NY, USA
Correspondence: Ankita Modi Center for Observational and RealWorld Evidence Supporting Bone Products, Merck \& Co., Inc., 600 Corporate Drive, Lebanon, NJ 08833, USA

Tel +l 9082364563

Fax + I 9082364089

Email ankita.modi@merck.com
Background: Preexisting gastrointestinal (GI) events may deter the use of pharmacologic treatment in patients diagnosed with osteoporosis (OP). The objective of this study was to examine the association between preexisting GI events and OP pharmacotherapy initiation among women diagnosed with OP.

Methods: The study utilized claims data from a large US managed care database to identify women aged $\geq 55$ years with a diagnosis code for OP (index date) during 2002-2009. Patients with a claim for pharmacologic OP treatment in the 12-month pre-index period (baseline) were excluded. OP treatment initiation in the post-index period was defined as a claim for bisphosphonates (alendronate, ibandronate, risedronate, zoledronic acid), calcitonin, raloxifene, or teriparatide. During the post-index period (up to 12 months), GI events were identified before treatment initiation. A time-dependent Cox regression model was used to investigate the likelihood of initiating any OP treatment. Among patients initiating OP treatment, a discrete choice model was utilized to assess the relationship between post-index GI events and likelihood of initiating with a bisphosphonate versus a non-bisphosphonate.

Results: In total, 65,344 patients (mean age 66 years) were included; $23.7 \%$ had a GI event post diagnosis and before treatment initiation. Post-index GI events were associated with a $75 \%$ lower likelihood of any treatment initiation (hazard ratio $0.25 ; 95 \%$ confidence interval $0.24-0.26)$. Among treated patients $(n=23,311)$, those with post-index GI events were $39 \%$ less likely to receive a bisphosphonate versus a non-bisphosphonate (odds ratio $0.61 ; 95 \%$ confidence interval 0.54-0.68).

Conclusion: GI events after OP diagnosis were associated with a decreased likelihood of OP treatment initiation and an increased likelihood of treatment initiation with a non-bisphosphonate versus a bisphosphonate.

Keywords: osteoporosis, postmenopausal, bisphosphonates, prescribing patterns

\section{Introduction}

Recent estimates suggest that $15.4 \%$ of US women aged 50 years or older have osteoporosis (OP) and an additional 51.4\% have evidence of low bone density. ${ }^{1}$ An increased risk of fracture is the most significant consequence of OP and low bone density. There were an estimated 2 million OP-related fractures in the USA in 2005 and the number of fractures is projected to increase to more than 3 million annually by $2025 .^{2}$ Pharmacologic treatment for OP can reduce fracture risk, and is appropriate for many patients with OP. A previous study concluded that $30 \%$ of US women aged 50 years or older warrant consideration for OP treatment, based on their risk for fracture. ${ }^{3}$ Currently, several therapies are approved for OP treatment by the US Food and Drug Administration to reduce fracture risk, including bisphosphonates 
(alendronate, ibandronate, risedronate, zoledronic acid), calcitonin, raloxifene, teriparatide, and denosumab. ${ }^{4}$

Despite the availability of multiple treatment options, recent studies indicate a substantial proportion of US women at risk of fracture remain untreated. In the US cohort of the Global Longitudinal Study of Women, only $65 \%$ of women with a self-reported diagnosis of OP reported taking antiresorptive treatment. ${ }^{5}$ Studies based on electronic medical records or administrative claims documentation of pharmacologic OP treatment initiation suggest under-treatment is considerably greater. ${ }^{6,7}$ In a Pennsylvania study, less than $20 \%$ of women who had experienced a fracture were receiving oral bisphosphonate in the year following the fracture, and only $49 \%$ of women with an OP diagnosis or T-score indicative of OP received bisphosphonate treatment within 1 year of their diagnosis or bone mineral density test result. ${ }^{6}$ A study of a national US claims database reported that only $36 \%$ of women had evidence of receipt of any OP treatment in the first year following their OP diagnosis. ${ }^{7}$

The barriers to treatment initiation are not well understood. Certain patient characteristics appear to decrease the likelihood of treatment, including younger age, lower education level, higher bone mineral density T-score, higher body mass index, and lack of concomitant corticosteroid use. ${ }^{6,8,9}$ Patient concern over OP medication side effects has also been linked with nontreatment initiation. ${ }^{10}$ Physicians may also be unwilling to prescribe OP treatment for their patients with OP due to concurrent medical conditions. Bisphosphonates are the most widely prescribed therapy and contraindicated for patients with severe renal insufficiency. Yet, a study of electronic medical records found that the most common reason (28\%) for not prescribing bisphosphonates to patients diagnosed with OP was a preexisting gastrointestinal (GI) diagnosis. ${ }^{11}$ Among patients who do initiate OP treatment, GI intolerance has also been cited as a common cause for OP treatment discontinuation. ${ }^{12-14}$ However, the risk of GI events while on OP treatment is also a function of preexisting GI conditions. ${ }^{15}$

The relationship between preexisting GI events and treatment initiation has not been well explored in a managed care population in the USA. The objective of this study was to examine the association between preexisting GI events and likelihood of treatment initiation among women diagnosed with OP within a managed care setting in the USA.

\section{Materials and methods Study design}

A retrospective cohort study was conducted using a large national claims database known as the Optum Insight
Clinformatics Data Mart. This database was designed to primarily support health care outcomes research and other research initiatives. The database includes demographic, medical, and pharmacy claims for more than 80 million managed care enrollees in more than 45 health plans throughout the USA. Over 3 million patients with OP were included in the database during the study period from January 2001 to December 2010. All study data were de-identified and accessed using techniques compliant with the Health Insurance Portability and Accountability Act; therefore, Institutional Review Board approval was not required.

Within the study period - January 1, 2001 to December 31, 2010 - an index date was assigned during January 1, 2002 to December 31, 2009. The index date was defined as the date of the first OP diagnosis observed. The 1-year period before the index date represented the pre-index period, while the postindex period began the day after the index date and lasted for 12 months or until the date that OP medications were initiated, if less than 12 months. Therefore, patients who did not initiate OP treatment had a full 12 months of follow-up, while those who initiated treatment had less than 12 months of follow-up.

\section{Study sample}

Women aged 55 years or older on the index date with a primary or secondary diagnosis of OP (International Classification of Diseases, Ninth Revision, Clinical Modification [ICD-9-CM] code 733.0x) were included. Patients were required to be continuously enrolled in the health plan for at least 1 year before and 1 year after the index date, and to be OP treatment-naïve, defined as no claims for OP medications prior to the index date. Patients were excluded if they had evidence of estrogen therapy in the pre-index period, a diagnosis of malignant neoplasm (ICD-9-CM codes 140$170,173-208,230-239)$ in the pre-index period or in the 1 year after the index date, or any claim for Paget's disease (ICD-9-CM code 731.0) ever in the claims history.

\section{Measures}

The occurrence of a GI event was defined by the presence of a claim with a GI-related ICD-9-CM diagnostic or Current Procedural Terminology code (see Table S1), including esophagitis, esophageal reflux, ulcer, stricture, perforation, hemorrhage of esophagus, gastric ulcer, duodenal ulcer, peptic ulcer, acute gastritis, duodenitis, GI hemorrhage, nausea or vomiting, and dysphagia. GI events were separately captured for the pre-index and post-index periods.

Patients who received at least one OP medication during the post-index period were characterized as "treated", 
while all others were considered to be "untreated". OP medications were identified based on National Drug Codes and Healthcare Common Procedure Coding System codes, and included all forms (oral, injectable, infused) of bisphosphonates (alendronate, ibandronate, risedronate, zoledronic acid) and all forms of non-bisphosphonates (calcitonin, raloxifene, and teriparitide). Denosumab was excluded because it was not approved until June 2010, near the end of the study period. Classifications of OP medications were determined by National Drug Codes (Table S1). Patient age was determined on the index date. The pre-index Charlson Comorbidity Index (CCI) score was computed. ${ }^{16}$ The CCI is used to predict the mortality of a patient based on the occurrence of 19 predefined comorbid conditions. Higher CCI denotes higher mortality. The presence of comorbid conditions, fracture history, and medication use (gastroprotective agents, nonsteroidal anti-inflammatory drugs [NSAIDs], and glucocorticoids) were also determined during the pre-index period. Fractures during the pre-index period were identified from ICD-9-CM codes (Table S1).

\section{Statistical analysis}

Patient characteristics were summarized for the entire cohort as well as by the presence or absence of a pre-index GI event. For continuous variables (age and CCI score), means and standard deviations were calculated. The number and proportion of patients with pre-index comorbid conditions, pre-index fractures, pre-index medication use, and pre-index and post-index GI events were tabulated. Comparisons of baseline characteristics between patients with and without a pre-index GI event were performed using $\chi^{2}$ tests for categorical variables and $t$-tests for continuous variables.

To determine the timing and type of OP treatment initiation, prescription claims after the index date were searched, and used to classify patients as receiving "no treatment", "bisphosphonates", or "non-bisphosphonates". The proportion of patients in each classification was calculated and compared between patients with and without post-index GI events. $\chi^{2}$ tests were used to compare the treatment distributions of patients with and without GI events.

Time-varying Cox regression (which takes into consideration the timing of the post-index GI events before treatment initiation) was used to estimate the likelihood of treatment initiation for any OP treatment, stratified by the presence of pre-index GI events. For treated patients, a discrete choice model was used to estimate the likelihood of receiving a bisphosphonate versus a non-bisphosphonate. In the Cox model and the discrete choice model, the independent variable of interest was the presence of a post-index GI event; models were also adjusted for the presence of pre-index GI events (discrete choice model only), age group, pre-index medication use (gastroprotective agents, NSAIDs, glucocorticosteroids), pre-index CCI, and selected pre-index comorbidities (chronic inflammatory bowel disease, chronic inflammatory joint disease, celiac disease, diabetes, depression, chronic kidney failure, hypertension, GI mucositis and urination problems, hyperparathyroidism, vitamin D deficiency, and fatigue). The Cox regression model separately quantified the effects of a post-index GI event for those with and without pre-index GI events.

\section{Results \\ Patient characteristics}

A total of 65,344 women were identified for analysis (Figure 1). The average age at diagnosis was 65.7 years, and 17,828 patients $(27.3 \%)$ experienced a GI event during the pre-index period (Table 1). Among all patients, the most

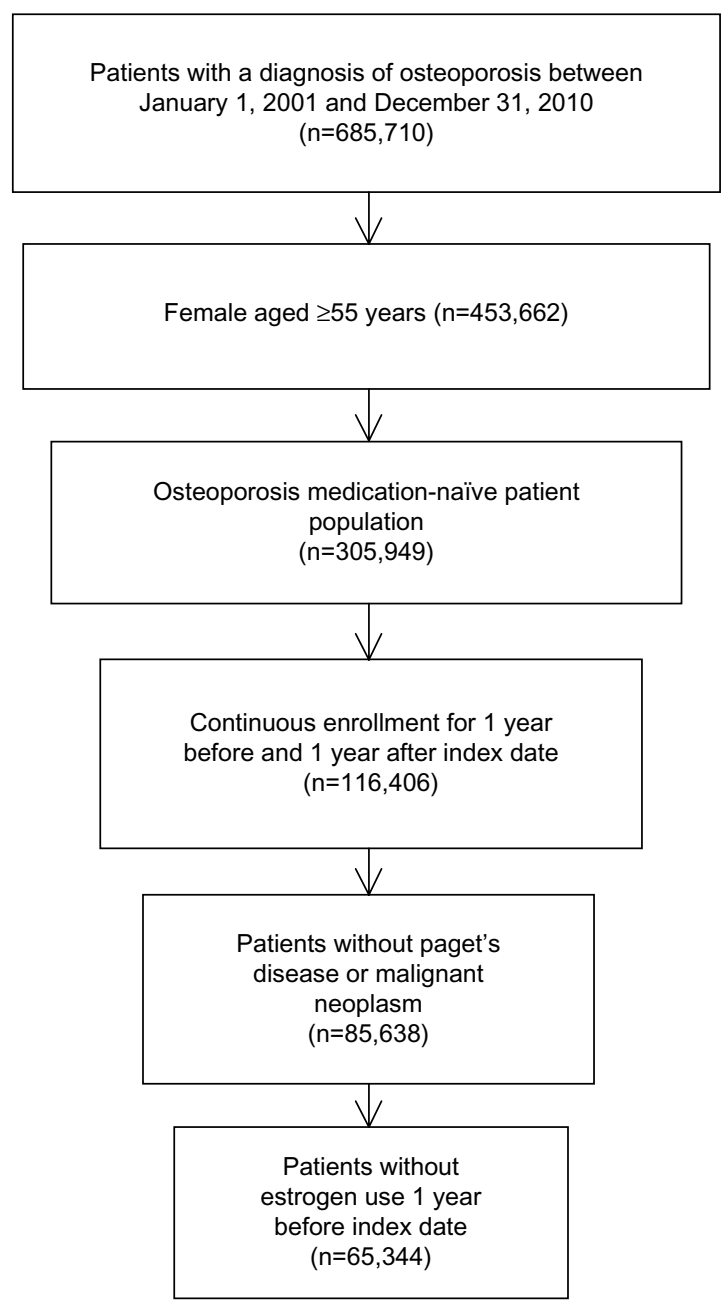

Figure I Patient selection. 
Table I Patient characteristics in the pre-index period ${ }^{a}$

\begin{tabular}{|c|c|c|c|c|}
\hline & $\begin{array}{l}\text { All patients } \\
(n=65,344)\end{array}$ & $\begin{array}{l}\text { Without pre-index GI event } \\
(n=47,5 \mid 6)\end{array}$ & $\begin{array}{l}\text { With pre-index Gl event } \\
(n=17,828)\end{array}$ & $P$-value \\
\hline Pre-index Gl event & I 7,828 (27.3) & - & I7,828 (27.3) & \\
\hline Age (years), mean (SD) & $65.7(8.9)$ & $65.5(8.8)$ & $66.2(9.1)$ & $<0.00$ I \\
\hline $55-64$ & $37,201(56.9)$ & $27,432(57.7)$ & $9,769(54.8)$ & - \\
\hline $65-74$ & $|4| ,48(2 \mid .7)$ & $10,296(21.7)$ & $3,852(21.6)$ & - \\
\hline $75-84$ & $12,837(19.7)$ & $9,044(19.0)$ & $3,793(21.3)$ & - \\
\hline $85+$ & $\mathrm{I}, \mathrm{I} 58(\mathrm{I} .8)$ & $744(1.6)$ & $4 \mid 4(2.3)$ & - \\
\hline \multicolumn{5}{|l|}{ Medication use } \\
\hline Gastroprotective agents & $10,185(15.6)$ & $3,444(7.3)$ & $6,74 I(37.8)$ & $<0.00$ I \\
\hline NSAIDs & $\mid 4,103(2 \mid .6)$ & $9,399(19.8)$ & $4,704(26.4)$ & $<0.00$ I \\
\hline Glucocorticoids & 8,917 (13.7) & $5,570(I I .7)$ & $3,347(18.8)$ & $<0.001$ \\
\hline $\mathrm{CCl}$ score, mean (SD) & $0.65(1.12)$ & $0.52(0.96)$ & $\mathrm{I} .0 \mathrm{I}(\mathrm{I} .4 \mathrm{I})$ & $<0.001$ \\
\hline \multicolumn{5}{|l|}{ Comorbidities } \\
\hline Chronic inflammatory bowel disease & $468(0.7)$ & $199(0.4)$ & $269(1.5)$ & $<0.00$ I \\
\hline Chronic inflammatory joint disease & $13,922(21.3)$ & $8,817(18.6)$ & $5,105(28.6)$ & $<0.001$ \\
\hline Celiac disease & $223(0.3)$ & $88(0.2)$ & $135(0.8)$ & $<0.001$ \\
\hline Diabetes & $9,211(14.1)$ & $6,094(12.8)$ & $3,117(17.5)$ & $<0.00$ I \\
\hline Depression & $3,759(5.8)$ & $2,106(4.4)$ & $\mathrm{I}, 653(9.3)$ & $<0.001$ \\
\hline Chronic kidney disease & $882(1.4)$ & $45 I(1.0)$ & $431(2.4)$ & $<0.001$ \\
\hline Hypertension & $3 I, 447(48.1)$ & $21,164(44.5)$ & $10,283(57.7)$ & $<0.001$ \\
\hline GI mucositis and urination problems & $4,830(7.4)$ & $2,623(5.5)$ & $2,207(12.4)$ & $<0.00$ I \\
\hline Hyperparathyroidism & $366(0.6)$ & $219(0.5)$ & $147(0.8)$ & $<0.001$ \\
\hline Vitamin D deficiency & $365(0.6)$ & $219(0.5)$ & $146(0.8)$ & $<0.00$ I \\
\hline Fatigue & $10,712(16.4)$ & $6,469(13.6)$ & $4,243(23.8)$ & $<0.001$ \\
\hline \multicolumn{5}{|l|}{ Fractures } \\
\hline Any & $4,476(6.9)$ & $2,867(6.0)$ & $1,609(9.0)$ & $<0.001$ \\
\hline Hip & 991 (I.5) & $604(1.3)$ & $387(2.2)$ & $<0.001$ \\
\hline Vertebral & $1,256(1.9)$ & $688(1.5)$ & $568(3.2)$ & $<0.001$ \\
\hline Non-vertebral & $2,864(4.4)$ & $1,918(4.0)$ & $946(5.3)$ & $<0.001$ \\
\hline
\end{tabular}

Notes: ${ }^{a}$ Values are presented as $\mathrm{n}(\%)$ unless otherwise indicated; ${ }^{\mathrm{P}} \mathrm{P}$-values are for the comparison between patients with and without a pre-index $\mathrm{Gl}$ diagnosis. Abbreviations: $\mathrm{CCl}$, Charlson Comorbidity Index; GI, gastrointestinal; SD, standard deviation; NSAID, nonsteroidal anti-inflammatory drug.

common comorbid conditions were hypertension (48\%), chronic inflammatory joint disease (21\%), and fatigue (16\%). Patients with a pre-index GI event were more likely to have each of the comorbid conditions evaluated than patients without a pre-index GI event $(P<0.001)$. Patients with a pre-index GI event were more likely to use gastroprotective agents $(37.8 \%$ versus $7.3 \%)$, NSAIDs $(26.4 \%$ versus $19.8 \%)$, and glucocorticoids (18.8\% versus $11.7 \%)$ than patients without a pre-index GI event $(P<0.001)$. The occurrence of a GI event during the pre-index GI event was also associated with a higher mean CCI score (1.01 versus $0.52, P<0.001)$ and a higher rate of fractures $(9.0 \%$ versus $6.0 \%, P<0.001)$.

\section{Osteoporosis treatment}

The frequency of OP treatment within this cohort has been previously reported.7 Briefly, 42,033 (64.3\%) patients received no OP medication within the first year following the OP diagnosis. A total of 23,311 (35.7\%) patients received treatment: $20,200(30.9 \%)$ with a bisphosphonate and 3,111 $(4.9 \%)$ with a non-bisphosphonate. ${ }^{7}$

\section{$\mathrm{Gl}$ events and OP treatment initiation}

Overall, 24\% of all patients experienced a GI event in the postindex period, although GI events were more common among those who had experienced a pre-index GI event $(43.4 \%$ versus $16.2 \%$, Table 2 ). The rate of pre-index GI events was similar among patients who did and did not initiate treatment (bisphosphonate or non-bisphosphonate, Figure 2A). However, the occurrence of post-index GI events appeared

Table 2 Distribution of $\mathrm{Gl}$ events in the pre-index and postindex periods

\begin{tabular}{llll}
\hline $\begin{array}{l}\text { Pre-index } \\
\text { period }\end{array}$ & \multicolumn{2}{l}{ Post-index period } & \multirow{2}{*}{ Total } \\
\cline { 2 - 3 } & No Gl events & Gl events & \\
\hline No Gl events & $39,800(83.8 \%)$ & $7,716(16.2 \%)$ & $47,516(72.7 \%)$ \\
Gl events & $10,090(56.6 \%)$ & $7,738(43.4 \%)$ & $17,828(27.3 \%)$ \\
Total & $49,890(76.3 \%)$ & $15,454(23.7 \%)$ & 65,344 \\
\hline
\end{tabular}

Abbreviation: $\mathrm{Gl}$, gastrointestinal. 


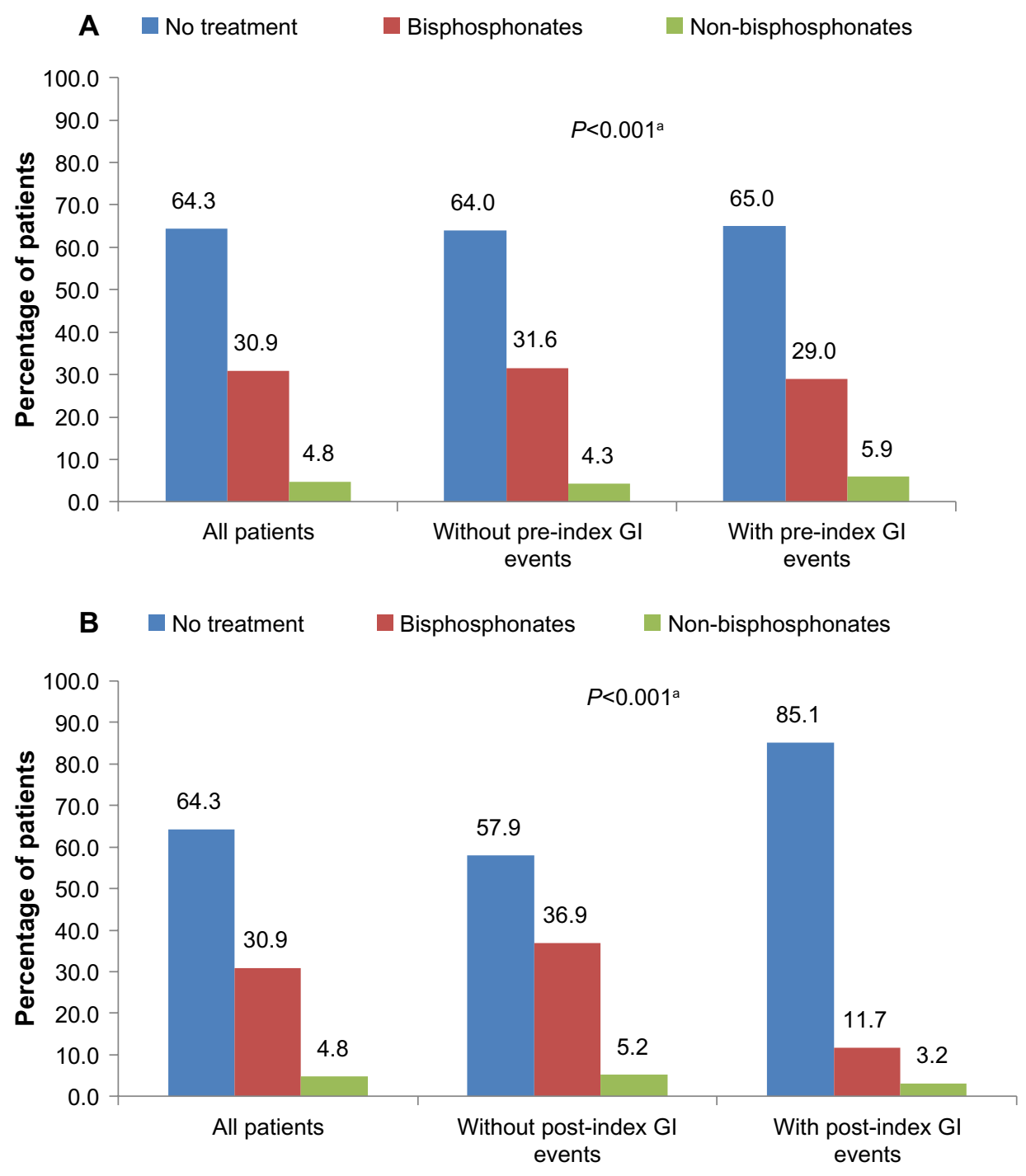

Figure 2 Treatment with medications for osteoporosis in the post-index period by (A) pre-index $\mathrm{Gl}$ events and (B) post-index $\mathrm{Gl}$ events. Note: a Comparison of treatment pattern distribution among patients with and without $\mathrm{Gl}$ events.

Abbreviation: $\mathrm{Gl}$, gastrointestinal.

to be associated with OP treatment initiation (Figure 2B). The proportion of patients receiving no OP treatment was $85.1 \%$ among patients with a post-index GI event versus $57.9 \%$ among patients with no post-index GI event. Among treated patients, $11.7 \%$ of patients with a postindex GI event initiated treatment with a bisphosphonate compared with $36.9 \%$ of patients without a post-index GI event.

\section{Multivariate analysis for association between $\mathrm{Gl}$ events and OP treatment initiation}

The results of the time-varying Cox regression model for the association between post-index GI events and any OP treatment (bisphosphonate or non-bisphosphonate) initiation are shown in Table 3. Among all covariates included in the analysis, the occurrence of post-index GI events had the greatest impact on OP treatment initiation. Patients who experienced post-index GI events were $75 \%$ less likely to initiate OP treatment than patients without post-index GI events (hazard ratio $0.25 ; 95 \%$ confidence interval [CI] $0.24-0.26 ; P<0.0001)$. Hypertension, chronic inflammatory joint disease, and diabetes were also significantly associated with a lower likelihood of OP treatment initiation $(P \leq 0.04)$, while depression and use of gastroprotective agents, NSAIDs, and glucocorticoids were associated with a higher likelihood of treatment initiation $(P<0.001)$.

The results of the discrete choice model among patients who initiated OP treatment are shown in Table 4. Patients with a post-index GI event were $39 \%$ less likely to receive 
Table 3 Time-varying Cox regression model for the association between post-index $\mathrm{Gl}$ events and any osteoporosis treatment (bisphosphonate or non-bisphosphonate) initiation

\begin{tabular}{|c|c|c|c|}
\hline Independent variable & Hazard ratio & $95 \% \mathrm{Cl}$ & $P$-value \\
\hline Post-index Gl events & 0.25 & $(0.24-0.26)$ & $<0.0001$ \\
\hline Age group, years & & & 0.081 \\
\hline $65-74$ versus $55-64$ & 1.01 & $(0.98-1.05)$ & \\
\hline $75-84$ versus $55-64$ & 1.00 & $(0.96-1.03)$ & \\
\hline $85+$ versus $55-64$ & 0.87 & $(0.78-0.98)$ & \\
\hline \multicolumn{4}{|l|}{ Pre-index medication use } \\
\hline Gastroprotective agents & 1.46 & $(I .4|-| .52)$ & $<0.000$ I \\
\hline NSAIDs & 1.20 & $(1.16-1.24)$ & $<0.000$ I \\
\hline Corticosteroids & 1.18 & $(1.13-1.22)$ & $<0.000$ I \\
\hline $\begin{array}{l}\text { Charlson comorbidity } \\
\text { index score }\end{array}$ & 1.01 & $(0.99-1.03)$ & 0.191 \\
\hline \multicolumn{4}{|l|}{ Comorbidity } \\
\hline $\begin{array}{l}\text { Chronic inflammatory } \\
\text { bowel disease }\end{array}$ & 1.08 & $(0.93-1.26)$ & 0.309 \\
\hline $\begin{array}{l}\text { Chronic inflammatory } \\
\text { joint disease }\end{array}$ & 0.86 & $(0.83-0.89)$ & $<0.0001$ \\
\hline Celiac disease & 1.08 & $(0.88-1.36)$ & 0.420 \\
\hline Diabetes & 0.80 & $(0.77-0.84)$ & $<0.0001$ \\
\hline Depression & 1.06 & $(1.00-1.12)$ & 0.044 \\
\hline Chronic kidney disease & 1.02 & $(0.89-1.16)$ & 0.780 \\
\hline Hypertension & 0.88 & $(0.85-0.90)$ & $<0.000$ I \\
\hline $\begin{array}{l}\text { GI mucositis and } \\
\text { urination problems }\end{array}$ & 0.97 & $(0.92-1.02)$ & 0.282 \\
\hline Hyperparathyroidism & 0.97 & $(0.81-1.17)$ & 0.767 \\
\hline Vitamin D deficiency & 0.91 & $(0.76-1.08)$ & 0.279 \\
\hline Fatigue & 1.00 & $(0.96-1.03)$ & 0.851 \\
\hline
\end{tabular}

Abbreviations: $\mathrm{Cl}$, confidence interval; GI, gastrointestinal; NSAIDs, nonsteroidal anti-inflammatory drugs.

a bisphosphonate than a non-bisphosphonate compared with those without a post-index GI event (odds ratio $0.61 ; 95 \% \mathrm{CI}$ $0.54-0.68 ; P<0.0001)$. A pre-index GI event, older age, and use of gastroprotective agents also significantly decreased the likelihood of bisphosphonate treatment initiation but to a lesser extent than post-index GI events. Comorbid diabetes predicted a slightly higher likelihood of treatment initiation with a bisphosphonate, and GI mucositis and urinary problems were associated with a lower likelihood of treatment initiation with a bisphosphonate.

\section{Discussion}

In this population of US women diagnosed with OP, a majority $(64.3 \%)$ received no OP medication in the year following their OP diagnosis. GI events in the post-index period strongly decreased the likelihood of initiating any treatment for OP. Among patients who initiated treatment, the presence of a GI event in the post-index period also decreased the likelihood of treatment with a bisphosphonate versus a non-bisphosphonate.
Table 4 Discrete choice model examining the association between post-index $\mathrm{Gl}$ events and receipt of bisphosphonate among patients who initiated osteoporosis treatment

\begin{tabular}{|c|c|c|c|}
\hline $\begin{array}{l}\text { Independent variable } \\
\text { (reference: non- } \\
\text { bisphosphonate initiation) }\end{array}$ & Odds ratio & $95 \% \mathrm{Cl}$ & $P$-value \\
\hline Pre-index Gl events & 0.85 & $(0.78-0.94)$ & 0.001 \\
\hline Post-index $\mathrm{Gl}$ events & $0.6 \mathrm{I}$ & $(0.54-0.68)$ & $<0.000$ I \\
\hline \multicolumn{4}{|l|}{ Age group, years } \\
\hline $65-74$ versus $55-64$ & 0.96 & $(0.87-1.06)$ & 0.442 \\
\hline $75-84$ versus $55-64$ & 0.79 & $(0.7 \mathrm{I}-0.87)$ & $<0.0001$ \\
\hline $85+$ versus $55-64$ & 0.72 & $(0.54-0.97)$ & 0.029 \\
\hline \multicolumn{4}{|l|}{ Pre-index medication use } \\
\hline Gastroprotective agents & 0.68 & $(0.62-0.76)$ & $<0.0001$ \\
\hline NSAIDs & 1.07 & $(0.97-1.17)$ & 0.184 \\
\hline Corticosteroids & 0.98 & $(0.88-1.09)$ & 0.733 \\
\hline $\begin{array}{l}\text { Charlson comorbidity index } \\
\text { score }\end{array}$ & 0.96 & $(0.92-1.01)$ & 0.096 \\
\hline \multicolumn{4}{|l|}{ Comorbidity } \\
\hline $\begin{array}{l}\text { Chronic inflammatory } \\
\text { bowel disease }\end{array}$ & 0.99 & $(0.65-I .5 I)$ & 0.953 \\
\hline $\begin{array}{l}\text { Chronic inflammatory joint } \\
\text { disease }\end{array}$ & 1.05 & $(0.95-1.17)$ & 0.320 \\
\hline Celiac disease & 0.72 & $(0.4 I-I .26)$ & 0.248 \\
\hline Diabetes & 1.22 & $(I .05-1.4 I)$ & 0.009 \\
\hline Depression & 1.11 & $(0.94-1.31)$ & 0.232 \\
\hline Chronic kidney disease & 0.90 & $(0.64-1.28)$ & 0.565 \\
\hline Hypertension & 1.06 & $(0.97-1.15)$ & 0.195 \\
\hline $\begin{array}{l}\text { Gl mucositis and urination } \\
\text { problems }\end{array}$ & 0.86 & $(0.75-0.99)$ & 0.040 \\
\hline Hyperparathyroidism & 1.14 & $(0.66-1.98)$ & 0.635 \\
\hline Vitamin D deficiency & 1.19 & $(0.68-2.10)$ & 0.540 \\
\hline Fatigue & 1.04 & $(0.93-1.16)$ & 0.474 \\
\hline
\end{tabular}

Abbreviations: $\mathrm{Cl}$, confidence interval; $\mathrm{Gl}$, gastrointestinal; NSAIDs, nonsteroidal anti-inflammatory drugs.

While published data regarding the association of GI events and OP treatment is limited, some research suggests a possible relationship. In a study of elderly women who had recently experienced a fracture, preexisting GI disease was associated with a modest but nonsignificantly lower odds of receiving treatment. ${ }^{17}$ Foster et al reported that certain preexisting GI conditions increased the likelihood of treatment with raloxifene versus bisphosphonates in a commercial/ Medicare cohort (but not a Medicaid cohort). ${ }^{18}$ However, the proportion of patients who experienced a post-index GI event prior to treatment initiation in our study was significantly higher than that observed by Foster et al (24\% versus $1 \%-3 \%$ ). In addition, the definition of what constituted a GI event differed, as we used a more comprehensive series of codes and examined the collective impact of all GI events on choice of OP treatment, rather than individual categories of GI events (eg, peptic ulcer and gastric ulcer). Our study also examined both baseline and post-index GI events. Our results indicate that baseline GI events did not appear to impact 
treatment initiation, but GI events that more closely coincided with OP diagnosis (ie, post-index GI events) strongly decreased the likelihood of treatment initiation. These results suggest that the clinical management of patients diagnosed with OP should take into account not only GI event history but also GI events that may occur after OP diagnosis.

Twenty-seven percentage of patients in this study had a GI event prior to their OP diagnosis and $23.7 \%$ experienced a GI event after their OP diagnosis (but before OP treatment initiation). In the POSSIBLE-US study, approximately 20\% of patients initiating OP medication reported GI symptoms at study entry. ${ }^{19}$ The higher rate of GI events we observed may be a function of the length of the observation period for GI events and the definition of GI events. We captured baseline GI events during the full 12-month period prior to diagnosis and post-OP diagnosis events up until treatment initiation or 12 months for patients who did not initiate treatment. We also relied on medical claims for documentation of a GI event. In contrast, the POSSIBLE-US study identified GI symptoms "at study entry" and was based on patient report. Irrespective of the methodologic differences, the results of both studies indicate that GI events are common among women with OP.

We found other patient characteristics also predicted OP treatment initiation, but to a lesser extent than post-index GI events. Use of gastroprotective agents, NSAIDS, and glucocorticoids prior to OP diagnosis were each significantly associated with an increased likelihood of receiving OP treatment. Previous studies have noted a similar association between glucocorticoid or corticosteroid use and treatment initiation. ${ }^{6,17,20}$ Although a higher comorbidity score was not associated with lower likelihood of treatment initiation, the presence of specific comorbid conditions (hypertension, chronic inflammatory disease, and diabetes) independently predicted lower likelihood of OP treatment initiation. Considering that diabetes and hypertension are common in the US population ${ }^{21,22}$ and that diabetes in particular has been linked with an increased risk of fracture in older women, ${ }^{23-25}$ the potential impact of comorbid conditions on treatment initiation warrants further research.

The reasons for not initiating treatment may lie with a physician's decision to not prescribe or patients not electing to receive treatment. GI disorders have been linked with physician prescribing patterns. A study of electronic medical records revealed that GI diagnoses were the most common $(28 \%)$ reason for not prescribing oral bisphosphonates to patients diagnosed with OP, followed by functional status (24\%) and renal impairment (12\%). ${ }^{11}$ Patients who did not initiate OP treatment are more likely to report a concern over OP medication side effects than patients who begin treatment, ${ }^{10}$ and the risk of GI side effects in particular may also influence patient treatment preferences. ${ }^{26}$ In a discrete choice experiment of preferred OP treatments, concern over the risk of GI side effects ranked higher than other side effects evaluated. ${ }^{26}$ Patients with preexisting GI disorders prior to treatment also have a high risk of experiencing GI events while on treatment, ${ }^{15}$ and GI side effects while on treatment are associated with worse adherence to treatment ${ }^{27}$ and greater likelihood of early treatment discontinuation. ${ }^{19,28,29}$ Our results coupled with previous research suggest that GI events may pose a significant barrier to effective treatment of OP.

This study is subject to the limitations inherent in a retrospective analysis of a claims database. Claims data are collected primarily for payment purposes, not research, and are subject to coding errors. The presence of a claim for a filled prescription does not necessarily indicate that the medication was taken or that it was taken as prescribed. In addition, this study was designed to assess all bisphosphonates as a group. However, different bisphosphonates may have different adverse effect profiles, ${ }^{30}$ and the timing (eg, daily versus monthly) and type (oral versus intravenous) of the dosing regimen may be a determinant of these profiles. ${ }^{12}$ The length of the study period (10 years) includes a span during which clinical patterns of bisphosphonate use may have been changing from daily to weekly regimens. ${ }^{31}$ From the available data, we are not able to ascertain why OP treatment was not initiated; it may reflect a clinical decision not to prescribe treatment or the failure of a patient to fill a prescription. Over-thecounter drugs such as low-dose NSAIDs and aspirin are not included in this analysis. Only GI events that resulted in medical service utilization were captured in this analysis; therefore, the association observed may reflect more severe GI events. Also, bone mineral density test results to support the claims diagnosis of OP were not available in the database. Finally, there may have been other unmeasured patient and clinician characteristics that influenced OP treatment initiation and receipt of a bisphosphonate versus a non-bisphosphonate treatment.

\section{Conclusion}

This study advances the understanding of how GI events impact treatment of OP. In a US managed care population of women with an incident diagnosis of OP, approximately one of four patients diagnosed with OP had a GI event post 
diagnosis and before treatment initiation, of whom $85 \%$ did not receive any treatment. Patients with a post-diagnosis GI event were $75 \%$ less likely to initiate treatment (versus those without a GI event). Among patients who initiated OP treatment, post-diagnosis GI events were associated with a $39 \%$ lower likelihood of initiation with a bisphosphonate compared with a non-bisphosphonate therapy. New therapies may be needed to address the unmet need for OP treatments for patients with prior and existing GI events.

\section{Acknowledgment}

Medical writing assistance was provided by Melissa Stauffer and Lauren Weisenfluh in collaboration with SCRIBCO, and was funded by Merck \& Co., Inc., Kenilworth, NJ, USA.

\section{Disclosure}

Study funding was provided by Merck \& Co, Inc., Kenilworth, NJ, USA. Ankita Modi, Shiva Sajjan and Shuvayu Sen are employees of Merck \& Co., Inc. Ethel S Siris has done consulting for Amgen, Eli Lilly, Merck, Novartis, AgNovos and Radius. Jackson Tang was a paid consultant to Merck in connection with this study and development of this manuscript.

\section{References}

1. Wright NC, Looker AC, Saag KG, et al. The recent prevalence of osteoporosis and low bone mass in the United States based on bone mineral density at the femoral neck or lumbar spine. J Bone Miner Res. 2014;29(11):2520-2526.

2. Burge R, Dawson-Hughes B, Solomon DH, Wong JB, King A, Tosteson A. Incidence and economic burden of osteoporosis-related fractures in the United States, 2005-2025. J Bone Miner Res. 2007; 22(3): 465-475.

3. Dawson-Hughes B, Looker AC, Tosteson AN, Johansson H, Kanis JA, Melton LJ 3rd. The potential impact of the National Osteoporosis Foundation guidance on treatment eligibility in the USA: an update in NHANES 2005-2008. Osteoporos Int. 2012;23(3):811-820.

4. Watts NB, Bilezikian JP, Camacho PM, et al. American Association of Clinical Endocrinologists Medical Guidelines for Clinical Practice for the diagnosis and treatment of postmenopausal osteoporosis. Endocr Pract. 2010;16 Suppl 3:1-37.

5. Guggina P, Flahive J, Hooven FH, et al. Characteristics associated with anti-osteoporosis medication use: data from the Global Longitudinal Study of Osteoporosis in Women (GLOW) USA cohort. Bone. 2012;51(6):975-980.

6. Asche C, Nelson R, McAdam-Marx C, Jhaveri M, Ye X. Predictors of oral bisphosphonate prescriptions in post-menopausal women with osteoporosis in a real-world setting in the USA. Osteoporos Int. 2010;21(8):1427-1436.

7. Siris ES, Modi A, Tang J, Gandhi S, Sen S. Substantial under-treatment among women diagnosed with osteoporosis in a US managed-care population: a retrospective analysis. Curr Med Res Opin. 2014;30(1): 123-130.

8. Brennan RM, Wactawski-Wende J, Crespo CJ, Dmochowski J. Factors associated with treatment initiation after osteoporosis screening. Am J Epidemiol. 2004;160(5):475-483.
9. Cole RP, Palushock S, Haboubi A. Osteoporosis management: physicians' recommendations and womens' compliance following osteoporosis testing. Women Health. 1999;29(1):101-115.

10. Yood RA, Mazor KM, Andrade SE, Emani S, Chan W, Kahler KH. Patient decision to initiate therapy for osteoporosis: the influence of knowledge and beliefs. J Gen Intern Med. 2008;23(11): $1815-1821$.

11. Kamneva O, Nye AM, Hamrick I. Reasons for bisphosphonate exclusion in patients treated for osteoporosis. Consult Pharm. 2011;26(5): 325-331.

12. Blumentals WA, Harris ST, Cole RE, Huang L, Silverman SL. Risk of severe gastrointestinal events in women treated with monthly ibandronate or weekly alendronate and risedronate. Ann Pharmacother. 2009;43(4):577-585.

13. Ettinger J, Pressman A, Schein J, Chan J, Silver P, Connolly N. Alendronate use among 812 women: prevalence, complaints, noncompliance with patient instructions J Managed Care Pharm. 1998: 488-492.

14. Hamilton B, McCoy K, Taggart H. Tolerability and compliance with risedronate in clinical practice. Osteoporos Int. 2003;14(3): 259-262.

15. Vestergaard P, Schwartz K, Pinholt EM, Rejnmark L, Mosekilde L. Gastric and esophagus events before and during treatment of osteoporosis. Calcif Tissue Int. 2010;86(2):110-115.

16. Deyo RA, Cherkin DC, Ciol MA. Adapting a clinical comorbidity index for use with ICD-9-CM administrative databases. J Clin Epidemiol. 1992;45(6):613-619.

17. Block AE, Solomon DH, Cadarette SM, Mogun H, Choudhry NK. Patient and physician predictors of post-fracture osteoporosis management. J Gen Intern Med. 2008;23(9):1447-1451.

18. Foster SA, Foley KA, Meadows ES, et al. Characteristics of patients initiating raloxifene compared to those initiating bisphosphonates. $B M C$ Womens Health. 2008;8:24.

19. Woo C, Gao G, Wade S, Hochberg MC. Gastrointestinal side effects in postmenopausal women using osteoporosis therapy: 1-year findings in the POSSIBLE US study. Curr Med Res Opin. 2010;26(4): 1003-1009.

20. Pressman A, Forsyth B, Ettinger B, Tosteson AN. Initiation of osteoporosis treatment after bone mineral density testing. Osteoporos Int. 2001;12(5):337-342.

21. Gillespie CD, Hurvitz KA; Centers for Disease Control and Prevention. Prevalence of hypertension and controlled hypertension - United States, 2007-2010. MMWR Surveill Summ. 2013;62 Suppl 3:144-148.

22. Centers for Disease Control and Prevention, National Center for Health Statistics, Division of Health Interview Statistics. Crude and age-adjusted percentage of civilian, noninstitutionalized adults with diagnosed diabetes, United States, 1980-2011. Available from: http://www.cdc.gov/diabetes/statistics/prev/national/figageadult.htm. Accessed September 22, 2014.

23. Nicodemus KK, Folsom AR; Iowa Women's Health Study. Type 1 and type 2 diabetes and incident hip fractures in postmenopausal women. Diabetes Care. 2001;24(7):1192-1197.

24. Schwartz AV, Sellmeyer DE, Ensrud KE, et al. Older women with diabetes have an increased risk of fracture: a prospective study. J Clin Endocrinol Metab. 2001;86(1):32-38.

25. Taylor BC, Schreiner PJ, Stone KL, et al. Long-term prediction of incident hip fracture risk in elderly white women: study of osteoporotic fractures. JAm Geriatr Soc. 2004;52(9):1479-1486.

26. Hiligsmann M, Dellaert BG, Dirksen CD, et al. Patients' preferences for osteoporosis drug treatment: a discrete-choice experiment. Arthritis Res Ther. 2014;16(1):R36.

27. Reynolds K, Viswanathan HN, O’Malley CD, et al. Psychometric properties of the osteoporosis-specific Morisky Medication Adherence Scale in postmenopausal women with osteoporosis newly treated with bisphosphonates. Ann Pharmacother. 2012;46(5): $659-670$. 
28. Lo JC, Pressman AR, Omar MA, Ettinger B. Persistence with weekly alendronate therapy among postmenopausal women. Osteoporos Int. 2006;17(6):922-928.

29. Yun H, Curtis JR, Guo L, et al. Patterns and predictors of osteoporosis medication discontinuation and switching among Medicare beneficiaries. BMC Musculoskelet Disord. 2014;15:112.

30. [No authors listed]. Management of osteoporosis in postmenopausal women: 2010 position statement of The North American Menopause Society. Menopause. 2010;17(1):25-54.
31. Gold DT, Bonnick SL, Amonkar MM, Kamel HK, Agarwal S, Zaidi M. Descriptive analysis of concomitant prescription medication patterns from 1999 to 2004 among US women receiving daily or weekly oral bisphosphonate therapy. Gend Med. 2008;5(4):374-384. 


\section{Supplementary material}

Table SI Codes used to identify gastrointestinal events, fractures, and use of bisphosphonates and non-bisphosphonates

\begin{tabular}{|c|c|c|}
\hline & Code & Description \\
\hline \multicolumn{3}{|l|}{ Gl events } \\
\hline \multirow[t]{22}{*}{ ICD-9-CM } & 456.0 & Esophageal varices with hemorrhage \\
\hline & 456.1 & Esophageal varices without hemorrhage \\
\hline & 530.xx & Diseases of esophagus \\
\hline & $531 . x x$ & Gastric ulcer \\
\hline & 532.xx & Duodenal ulcer \\
\hline & 533.xx & Peptic ulcer, site NOS \\
\hline & $534.0-3$ & Gastrojejunal ulcer \\
\hline & 535.xx & Gastritis and duodenitis \\
\hline & 536.2 & Persistent vomiting \\
\hline & 536.8 & Dyspepsia and other specified disorders of function of stomach \\
\hline & 536.9 & Stomach function disorders NOS \\
\hline & 537.4 & Gastric/duodenal fistula \\
\hline & $537.8 x$ & Gastroduodenal disorders NEC \\
\hline & 537.9 & Gastroduodenal disorders NOS \\
\hline & 569.83 & Perforation of intestine \\
\hline & 578.xx & Gl hemorrhage \\
\hline & $787.0 x$ & Nausea and vomiting \\
\hline & 787.1 & Heartburn \\
\hline & 787.2 & Dysphagia \\
\hline & $789.0 x$ & Abdominal pain \\
\hline & 792.1 & Abnormal stool/occult blood \\
\hline & 793.4 & Abnormal exam Gl tract \\
\hline \multirow[t]{15}{*}{ CPT } & 43200 & $\begin{array}{l}\text { Endoscopy, rigid or flexible; diagnostic, with or without collection of specimen(s) by brushing } \\
\text { or washing (separate procedure) }\end{array}$ \\
\hline & 43202 & $\begin{array}{l}\text { Esophagoscopy, rigid or flexible; diagnostic, with or without collection of specimen(s) by } \\
\text { brushing or washing (separate procedure) with biopsy, single or multiple }\end{array}$ \\
\hline & 43227 & $\begin{array}{l}\text { Esophagoscopy, rigid or flexible; diagnostic, with or without collection of specimen(s) by } \\
\text { brushing or washing (separate procedure) with control of bleeding, any method }\end{array}$ \\
\hline & 43235 & $\begin{array}{l}\text { Endoscopy, rigid or flexible; diagnostic, with or without collection of specimen(s) by brushing } \\
\text { or washing (separate procedure) }\end{array}$ \\
\hline & 43239 & $\begin{array}{l}\text { Upper Gl endoscopy including esophagus, stomach, and either the duodenum and/or jejunum } \\
\text { as appropriate; diagnostic with or without collection of specimen(s) by brushing or washing } \\
\text { (separate procedure) with biopsy, single or multiple }\end{array}$ \\
\hline & 43255 & $\begin{array}{l}\text { Upper Gl endoscopy including esophagus, stomach, and either the duodenum and/or jejunum } \\
\text { as appropriate; diagnostic with or without collection of specimen(s) by brushing or washing } \\
\text { (separate procedure), with control of bleeding, any method }\end{array}$ \\
\hline & 44602 & Suture of small intestine (enterorrhaphy) for perforated ulcer \\
\hline & 44603 & Suture of small intestine (enterorrhaphy) for perforated ulcer \\
\hline & 44605 & Suture of large intestine (colorrhaphy) for perforated ulcer \\
\hline & 74240 & Radiologic examination, GI tract, upper; with or without delayed film, without KUB \\
\hline & $7424 \mid$ & Radiologic examination, GI tract, upper; with or without delayed films, with KUB \\
\hline & 74245 & Radiologic examination, Gl tract, upper; with small bowel, includes multiple serial films \\
\hline & 74246 & $\begin{array}{l}\text { Radiologic examination, Gl tract, upper, air contrast, with specific high density barium, } \\
\text { effervescent agent, with or without glycagon; with or without delayed films, with KUB }\end{array}$ \\
\hline & 74247 & $\begin{array}{l}\text { Radiologic examination, Gl tract, upper, air contrast, with specific high density barium, } \\
\text { effervescent agent, with or without glycagon; with or without delayed films, without KUB }\end{array}$ \\
\hline & 74249 & $\begin{array}{l}\text { Radiologic examination, GI tract, upper, air contrast, with specific high density barium, } \\
\text { effervescent agent, with or without glycagon; with small bowel follow-through }\end{array}$ \\
\hline
\end{tabular}

Abbreviations: CPT, Current Procedural Terminology; GI, gastrointestinal; ICD-9-CM Dx, International Classification of Diseases, Ninth Revision, Clinical Modification diagnosis codes; KUB, kidney, ureter, and bladder X-ray; NEC, not elsewhere classifiable; NOS, not otherwise specified. 


\section{Publish your work in this journal}

ClinicoEconomics \& Outcomes Research is an international, peerreviewed open-access journal focusing on Health Technology Assessment, Pharmacoeconomics and Outcomes Research in the areas of diagnosis, medical devices, and clinical, surgical and pharmacological intervention. The economic impact of health policy and health systems organization also constitute important areas of coverage. The manuscript management system is completely online and includes a very quick and fair peer-review system, which is all easy to use. Visit http://www.dovepress.com/testimonials.php to read real quotes from published authors.

Submit your manuscript here: http://www.dovepress.com/clinicoeconomics-and-outcomes-research-journal 